\title{
Localized Scarlatiniform Rash of the Ears and Antecubital Fossa in COVID-19
}

\author{
Timothy Truong Phamduy, DO, Douglas Morris Young, DO, and \\ Paras Batuk Ramolia, MD
}

The worldwide spread of the novel coronavirus disease 2019 (COVID-19) caused by severe acute respiratory syndrome coronavirus 2 (SARS-CoV-2) has led to a global pandemic since its identification in Wuhan, China in December 2019. ${ }^{1}$ Few cases of COVID-19-associated dermatologic manifestations have been reported in the literature to date. This report describes the clinical features of a localized pruritic scarlatiniform rash of the ears and antecubital fossa on defervescence in a 29-year-old patient with COVID-19. Our case stands to further illuminate the dermatologic manifestations of this novel disease. (J Am Board Fam Med 2021;34:S183-S185.)

Keywords: Community Medicine, COVID-19, Dermatology, Exanthema, Family Medicine, Itching, Pandemics, Primary Health Care, Prurigo, Pruritus, Rash, Scarlet Fever

\section{Introduction}

The rapid, worldwide spread of the novel coronavirus disease 2019 (COVID-19) caused by severe acute respiratory syndrome coronavirus 2 (SARS$\mathrm{CoV}-2$ ) has led to a global pandemic since its identification in Wuhan, China in December 2019. ${ }^{1}$ The diagnosis is suspected clinically in patients who present with symptoms of fever, cough, dyspnea, myalgia, and fatigue and is confirmed via laboratory testing. ${ }^{2}$ Few cases of COVID-19-associated dermatologic manifestations have been reported in the literature to date. This report describes the clinical features of a cutaneous eruption of the ears and antecubital fossa in a patient with COVID-19.

\section{Case Report}

On 23 March 2020, a 29-year-old male health care worker presented to our outpatient clinic in

This article was externally peer reviewed.

Submitted 17 April 2020; revised 28 May 2020; accepted 2 June 2020.

From 7th Medical Group, Dyess Air Force Base, US Air Force, Abilene TX (TTP, DMY); Abilene Dermatology \& Skin Surgery Center, Abilene TX (PBR).

Funding: The authors received no specific funding for this work.

Conflict of interest: The authors declare that there are no conflicting or competing interests.

Corresponding author: Timothy Phamduy, DO, 1581 Varnum Avenue, Lowell, MA 01854 (Email: timothy. phamduy@gmail.com).
Abilene, Texas with a 2-day history of sore throat and dry cough. He also reported new-onset fever, myalgia, and fatigue, which started the morning of presentation. The patient's only significant dermatologic past medical history was alopecia areata, for which he received monthly intralesional steroid injections. His last injection was administered 1 month before presentation. He denied any recent travel or known sick contacts.

Physical examination revealed a body temperature of $38.8^{\circ} \mathrm{C}$, pulse of 101 beats per minute, and oxygen saturation of $95 \%$ while the patient was breathing ambient air. His breathing was unlabored. Rapid antigen detection tests for influenza A, influenza B, and group A streptococci were negative. Given that the patient was a health care worker, a nasopharyngeal swab was obtained to test for SARS-CoV-2 via real-time reverse-transcriptase-polymerase-chain-reaction (rRT-PCR) assay and was subsequently positive. Given clinical stability, the patient was instructed to self-isolate at home, monitor for clinical progression with daily temperature checks, and continue supportive therapy.

The patient reported taking 1 dose of an over-thecounter cold medication containing acetaminophen, dextromethorphan, and doxylamine the night before presentation and then a single dose of acetaminophen monotherapy the following 2 nights for throat pain. 
Two days after his initial presentation, day 5 of illness, the patient reported resolution of fevers and gradual improvement of his other presenting symptoms. He also noted the development of a pruritic, scarlatiniform, erythematous, papular eruption of the helical rim, antihelix, and earlobe. On day 6 of illness, the rash spread to circumferentially involve the elbows with greater involvement of the antecubital fossa (Figure 1). The rash gradually improved without therapy. By day 11 of illness, the eruption led to slight desquamation of the affected areas before complete resolution (Figure 2).

\section{Discussion}

Dermatologic manifestations of other coronaviruses have been previously reported in the literature. ${ }^{3,4}$ However, a complete understanding of the clinical spectrum of SARS-CoV-2 infection is still rapidly developing - ranging from asymptomatic carriers to acute respiratory distress syndrome and even death. ${ }^{1,5}$

Although SARS-COV-2 seems to have no demonstrated tropism for the skin, ${ }^{6}$ there have been reports of dermatologic manifestations of COVID19 patients. Guan et al. report a case series of 1099 patients of which 2 patients $(0.2 \%)$ had rashes that were not described further. ${ }^{7}$ Another case series from Lecco Hospital, Lombardo, Italy reports that

Figure 1. Image left elbow on day 11 of illness demonstrating a localized pruritic scarlatiniform of erythematous papules.

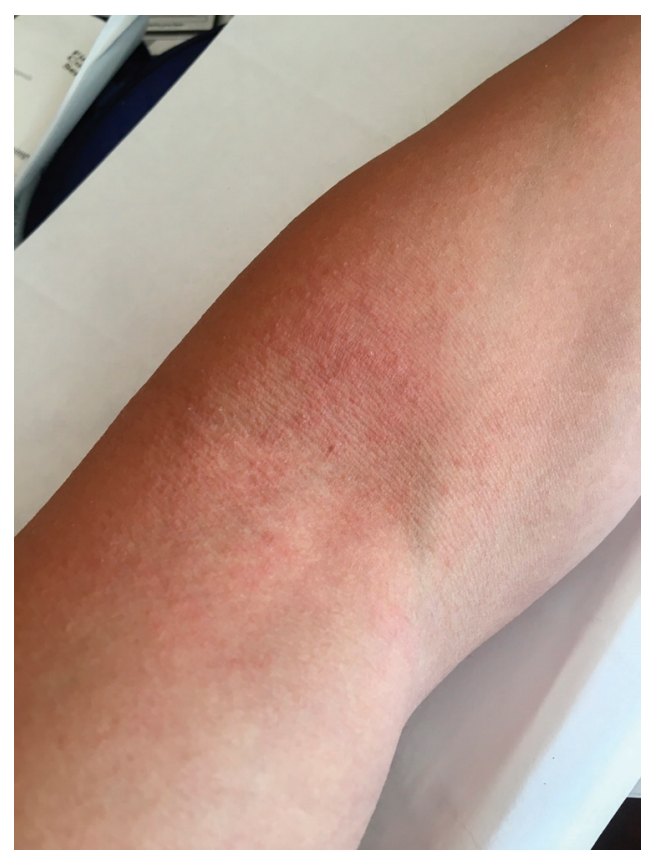

Figure 2. Image of the right ear demonstrating residual skin erythema and slight desquamation on day 11 of illness.

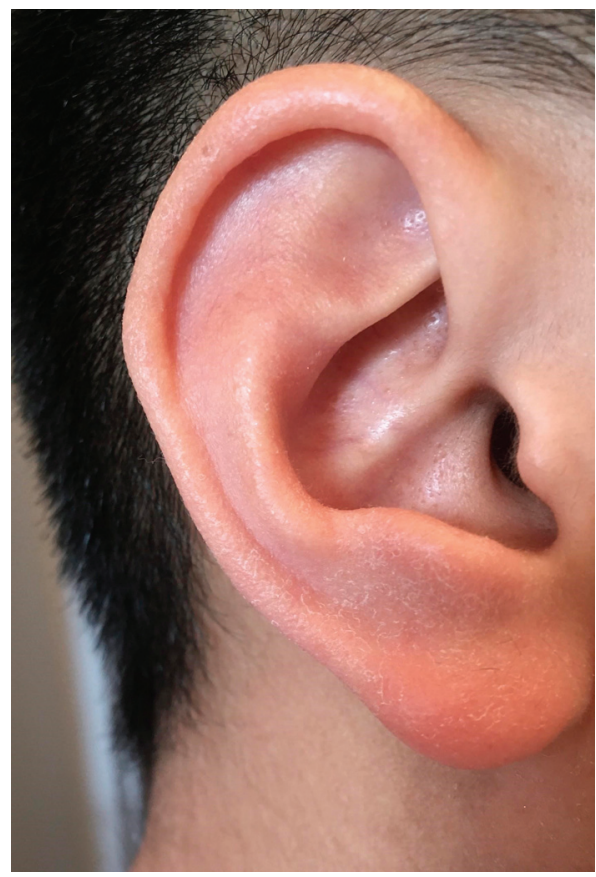

of the 88 confirmed COVID-19 positive patients they examined, 18 patients (20.4\%) had some form of cutaneous manifestation - erythematous rash, widespread urticaria, and varicella-like vesicles of primarily truncal distribution with low or absent pruritus. ${ }^{8}$ Case reports have also noted a denguelike petechial rash as well as a morbilliform, maculopapular, nonpruritic rash as presenting symptoms in patients subsequently diagnosed with COVID19. 910 Additional reports discuss a transient nonpruritic livedoid eruption and acro-ischemia of the extremities mimicking perniosis. ${ }^{1-14}$ Hoenig et al describe a self-resolving, erythematous, slightlyedematous rash of the malar region, neck, and ears of a 26-year-old patient with presumptive COVID19 based on close-contact exposure; however, due to shortages of SARS-CoV-2 testing kits, the patient was not tested. ${ }^{15}$ As had been noted with other coronaviruses, ${ }^{4}$ the dermatologic manifestations of Kawasaki disease in children have also been reported in association with SARS-CoV-2. ${ }^{16}$

Our patient's history of alopecia areata and the treatment he was undergoing may warrant consideration as a confounding factor. However, neither the autoimmune disorder, which causes nonscarring hair loss nor intralesional steroid injections, which may 
cause atrophy of the skin at the site of injection, have been known to cause rashes in unaffected areas as described in our case. ${ }^{17}$

Our report illustrates a case of a pruritic scarlatiniform rash of the ears and antecubital fossa after defervescence in a patient with confirmed SARSCoV-2. We feel our patient's rash adds to the growing body of data for clinical features of COVID-19 and is worth sharing with the medical community. Additional research and case reports will help further clarify the full clinical spectrum of COVID-19.

We thank Drs. Kleesy Thomas and Audra Cochran for their expertise and assistance throughout all aspects of our case report and for their help in the critical review of our manuscript.

To see this article online, please go to: http://jabfm.org/content/ 34/Supplement/S183.full.

\section{References}

1. Undiagnosed Pneumonia-China (HU): RFI. ProMEDmail 2019 Dec 30. Available from: promedmail. org/promed-post/?id=6864153. Accessed April 10, 2020.

2. Huang C, Wang Y, Li X, et al. Clinical features of patients infected with 2019 novel coronavirus in Wuhan, China. Lancet 2020;395:497-506.

3. Peiris JSM, Lai ST, Poon LLM, et al. Coronavirus as a possible cause of Severe Acute Respiratory Syndrome. Lancet 2003;361:1319-25.

4. Chang LY, Lu CY, Shao PL, et al. Viral infections associated with Kawasaki disease. J Formos Med Assoc 2014;113:148-54.

5. Rothe C, Schunk M, Sothmann $P$, et al. Transmission of 2019-nCoV infection from an asymptomatic contact in Germany. N Engl J Med 2020;382:970-1.

6. Yao XH, Li TY, He ZC, et al. A pathological report of three COVID-19 cases by minimally invasive autopsies. Zhonghua Bing Li Xue Za Zhi 2020;49: E009. Available from: http://dx.doi.org/10.3760/ cma.j.cn112151-20200312-00193.

7. Guan W, Ni Z, Hu Y, et al. Clinical characteristics of coronavirus disease 2019 in China. N Engl J Med 2020;382:1708-20. Available from: http://dx.doi.org/ 10.1056/NEJMoa2002032.
8. Recalcati S. Cutaneous manifestations in COVID-19: a first perspective. J Eur Acad Dermatol Venereol 2020;34:e212-13.

9. Joob B, Wiwanitkit V. COVID-19 can present with a rash and be mistaken for Dengue. J Am Acad Dermatol 2020;82:e177. Available from: http:// dx.doi.org/10.1016/j.jaad.2020.03.036.

10. Hunt M, Koziatek C. A case of COVID-19 pneumonia in a young male with full body rash as a presenting symptom. Clin Pract Cases in Emerg Med 2020;4:219-21. Available from: https://escholarship. org/uc/item/29j8q4pm\#author.

11. Zhang Y, Cao W, Xiao M, et al. Clinical and coagulation characteristics of 7 patients with critical COVID19 pneumonia and acro-ischemia. Zhonghua Xue Ye Xue Za Zhi 2020;41: E006. Available from: http:// dx.doi.org/10.3760/cma.j.issn.0253-2727.2020.0006.

12. Covid-19 and skin lesions: the French Dermatology Society calls for vigilance but also for caution. French Society of Sexually Transmitted Dermatology and Pathology 2020 Apr 08. Available from: https://www. sfdermato.org/media/pdf/actualite_slide/cp-lesionscutanees-covid-08042020vdefbis-5107ba5bb7ba4261ee 926df55350f90a.pdf. Accessed April 10, 2020.

13. Otto AM. Skin manifestations are emerging in the coronavirus pandemic. The Hospitalist Available from: https://www.sfdermato.org/media/pdf/actualite_ slide/cp-lesions-cutanees-covid-08042020vdefbis5107ba5bb7ba4261ee926df55350f90a.pdf. Accessed April 10, 2020.

14. Manalo IF, Smith MK, Cheeley J, Jacobs R. Dermatologic manifestation of COVID-19: transient livedo rerticularis. J Am Acad Dermatol 2020;83:700. Available from: http://dx.doi.org/ 10.1016/j.jaad.2020.04.018.

15. Hoenig LJ, Pereira FA. Eruption as a clinical manifestation of COVID 1:9 photographs of a patient. Clin Dermatol 2020; 38:502-5. Available from: http://dx.doi.org/10.1016/j.clindermatol.2020.04 .001 .

16. Jones VG, Mills M, Suarez D, et al. COVID-19 and Kawasaki disease: novel virus and novel case. Hosp Pediatr 2020;10:537-40. Available from: http://dx.doi.org/10.1542/hpeds.2020-0123.

17. Pratt $\mathrm{CH}$, King LE, Jr, Messenger AG, Christiana AM, Sundberg JP. Alopecia areata. Nat Rev Dis Primers 2017;3:17011. Available from: http://dx.doi.org/10.1038/nrdp.2017.11. 